\title{
Infection of Cardiac Implantable Electronic Devices: A Moroccan Single-Center Experience
}

\author{
Safae Harrak MD*, Fatima Chikhi MD, Fellat Btissam MD, Oukerraj Latifa MD, Cherti Mohamed MD
}

\author{
Cardiologie B Departement, Ibn Sina Hospital, University Mohamed V, Rabat, Morocco
}

DOI: $10.36347 /$ sasjm.2020.v06i02.002

| Received: 20.01.2020 | Accepted: 27.01.2020 | Published: 13.02.2020

*Corresponding author: Safae Harrak MD

Abstract

Original Research Article

Background: Increasing of Cardiac implantable electronic devices (CIEDs) have induced several complications such as infections. Our aim was to investigate the frequency of CIED infection, analyze the microbiological status and determinate contributing factors in order to prevent it. Patients and methods: We conducted a retrospective and descriptive study of patients who underwent implantation of electronic cardiac device in cardiology B department from January 2011 to June 2019. A total of 23 cases of CIED infection were identified. For each patient, all data were recorded about initial implantation of device and about CIED infection. Results: Frequency of CIED infection in our study is $1.2 \%$. According to British guidelines, isolated local infection (uncomplicated PI) is observed in 8 patients (34.7\%), local infection associated with sepsis (complicated PI) is found in 8 cases (34.7\%) and 5 patients (21.7\%) presented with systemic signs (ICED-LE and ICED-IE). Infection involve 17 patients with primary implantation and 6 patients after generator replacement. $78 \%$ of patients, male and $56 \%$ are young and ( $\leq 60$ years) and $39 \%$ are diabetics series is characterized by largest number of patients $(78 \%)$ who consult for local signs. Biological assessment and blood cultures didn't help to differentiate between local et systemic forms because blood tests were often negative. We noticed an increased negativity of bacteriological examinations. Conclusion: ICED-related infection affects, mainly, young male patients and frequently diabetics. These patients usually have been surgically revised for postoperative complications or underwent temporary wire before implantation. Often, it is systemic form induced by pocket infection. Biological and bacteriological tests are always negative. When the causative germ is isolated, it is often staphylococcus. Thus, implantation of CIED in these patients must be carefully performed especially in diabetics. Surgical revisions have to be avoided as much as possible.

Keywords: Cardiac implantable electronic device, Pocket infection, Risk factors, Percutaneous lead extraction.

Copyright @ 2020: This is an open-access article distributed under the terms of the Creative Commons Attribution license which permits unrestricted use, distribution, and reproduction in any medium for non-commercial use (NonCommercial, or CC-BY-NC) provided the original author and source are credited.

\section{INTRODUCTION}

Cardiac implantable electronic devices (CIEDs) are used to treat cardiac arrhythmias since they can regulate myocardial contractions. Recently, the indications for using CIEDs have been expanded. As a result, we have noted a significant increase in survival and an improvement in the quality of life of appropriate patients [1]. However, the increase in the rate of implantations of CIEDs has resulted in an increase in the number of complications, such as infections [2]. Such infections are severe with high rates of mortality [3]. They are difficult to manage because they often involve elderly patients with comorbidities, which contribute to a poor prognosis. Moreover, differences between local infections and systemic device infections can make diagnosis and therapeutic strategies more difficult.
The aims of this study are: (1) to assess the prevalence of these infections in our center, (2) to define the bacteriological profile so that we can increase the effectiveness of antibiotic prophylaxis used preoperatively, and (3) to identify the risk factors so that we can reduce the incidence of infection.

\section{METHODS \\ Study Population and Period}

We conducted a retrospective descriptive study of patients who underwent implantation of electronic cardiac device in cardiology B department from January 2011 to June 2019.

A total of 23 cases of CIED infection were identified in the study period. Thirteen (13) patients had their devices implanted at our center and ten (10) 
patients had their devices implanted outside hospital. There are no exclusion criteria for screening of patients.

\section{Definitions}

According to British guidelines for diagnosis, prevention and management of ICED infection established by A. T. Sandoe et al., [4], our patients were categorized into four groups:

- Early post-implantation inflammation

- Generator pocket infection (uncomplicated and complicated)

- ICED lead infection (ICED-LE)

- ICED-associated native or prosthetic valve endocarditis (ICED-IE)

\section{Data Sources}

We collected patients' data from medical records by following two steps:

- Data about initial implantation of device (date, type, first implantation or revision, indication of implantation, duration, complexity, procedural antibiotic use, postoperative complication). We don't know this information about six (6) patients operated outside the center.

- Data about CIED infection:

$>$ Demographic data (age, gender and origin)

$>$ Clinical data (co-morbidities, time of onset of infection compared to procedure, local or systemic symptoms)

$>$ Laboratory and microbiological data (blood cultures, device site cultures, complete blood count and inflammatory biomarkers tests)

$>$ Echocardiographic data (vegetation, localized thickening)

$>$ Treatment (intravenous antibiotic therapy, device extraction, reimplantation, surgery)

\section{STATISTICAL ANAL YSIS}

The aggregated data was filled in an Excel sheet, then we conduct a statistical analysis upon it. We transformed all variables about patients' data into tables and figures.

Quantitative variables are expressed in frequency $(\%)$ and qualitative variables are expressed in means and standard deviation and/or medians with inter-quartile ranges. We used two software in statistical study: "EPI Info version 3.6" and "SPSS version 13.0".

\section{RESULTS \\ Patient Characteristics}

The average age is 54.8 years \pm 18.6 . As shown in Figure-1, $56 \%$ of patients are young (under the age of 60). Moreover, the most affected age segment is 20-49 years. The sex ratio is 3.6 (78.2\% men and $21.8 \%$ women). Nine patients are hypertensive and nine are diabetic. Two patients have valvular prosthesis and under anticoagulant therapy.

\section{Procedure Prior to Infection}

In our series, infection involves 21 pacemakerimplanted patients (PM) and 2 patients with implanted cardiac resynchronization therapy devices (CRT-D). 14 patients have a dual-chamber pacemaker while 7 patients are implanted with a single-chamber one. Implantation of pacemaker was indicated for highdegree atrioventricular block in 22 patients and for bradyatrial fibrillation in a single patient. It is a primary implantation in 15 patients, and it is a generator replacement for 6 patients.

Regarding CRT-D, it was indicated for a rhythmic dilated cardiomyopathy in one patient and idiopathic dilated cardiomyopathy in the other patient.

Conditions of the intervention before the occurrence of the infection were studied in patients operated in our formation (there are 13). We know initial circumstances of 4 patients whom operated outside our hospital. However, we ignore it for 6 patients.

\section{The Infection}

\section{Incidence of Infection}

In the study period, incidence of infection in patients operated in our department is $1.2 \%$. This incidence doesn't include patients operated elsewhere.

\section{Type of infection and clinical finding:}

Isolated local infection (uncomplicated PI) was observed in 8 patients $(34.7 \%)$, local infection associated with sepsis (complicated PI) was found in 8 cases $(34.7 \%)$ and only 5 patients $(21.7 \%)$ presented systemic signs (ICED-LE and ICED-IE).

\section{Clinical Data}

Fever was present in 6 patients, and shivers in 5patients. A poor state of health was reported by 4 patients. Two patients reported dyspnea and 3 had lipothymia.

Local signs of infection; 12 patients presented with purulent discharge, 3 patients with non-purulent serositis and skin erosion with risk of externalization in 15 patients. Skin erythema was present in 6 patients.

\section{Symptoms Onset Delay}

Patients who presented the infection after a first implantation of pacemaker (or CRT-P) are 17. The average time of onset of symptoms is 381.8 days \pm 249.1. Patients who presented the infection after surgical revision are six. Within 4 patients, generator replacement was the only procedure that preceded the appearance of signs of infection. One patient underwent implantation of a new lead because of the fracture of the 
ventricular simultaneously with generator replacement. Consequently, the infectious symptoms appeared 91 days after this procedure. The other 3 patient's manifest symptoms within 602 days on average after generator replacement.

After generator change, two patients were revised for lead dysfunction. The delay of symptoms onset is 19 days and 188 days respectively after resumption.

\section{Biological Assessment}

Inflammatory biomarkers test (C-reactive protein (CRP), white blood count (WBC), erythrocyte sedimentation rate (VS), procalcitonin serum levels (PCT) had returned positive for only 6 patients $(26 \%)$. Skin swab of wound is negative in all patients. Cytobacteriological examination of pus is positive in 4 patients $(17.4 \%)$. The germs found are staphylococcus in 2 patients, seratia Marcecens in 1 patient and Streptococcus sobrii in 1 patient. Cytobacteriological examination of the material is positive in 7 patients. The germs found are staphylococcus (4patients), pseudonomonas (2) and seratia mascecens (1). Blood cultures is positive in 9 patients: it is a staphylococcus (6patients), hemophilusparainflenza and inflenza (1), enterobactercloacae (1) and serratialiquefaciens (1). Figure-2 shows bacteriogical data of blood culture, microbiological analysis of pus and lead-tip culture.

\section{Echocardiography Data}

Vegetation is found in 10 patients. It is localized on the atrial lead in 4 patients and on the ventricular lead in 6 patients. Its average size is $12 \mathrm{~mm}$ ranging from $5 \mathrm{~mm}$ to $30 \mathrm{~mm}$. Local thickening of the lead of pacemaker is found in 5 patients, it is located on the atrial lead in 2patients and ventricular lead in 3 patients.

\section{Therapeutic Approach}

Administration of antibiotic therapy began one day before the device extraction. We administered vancomycin with gentamycin within 11 patients, targocid with genta in 2patients and ceftriaxone with gentamycin in 9patients because of the unavailability of vancomycin. The average duration of antibiotic treatment is from 4 to 6 weeks. One patient underwent local revision without extraction. Percutaneous lead removal and reimplantation on the contralateral side has been considered in 12 patients. Reimplantation was considered with an average delay of 18.1 days compared to the date of removal. Three patients underwent extraction without reimplantation. Seven patients underwent open surgery removal that was indicated for difficulties of removal in two patients, large lead-associated vegetation in 3 patients and total externalization in 2patients.

\section{Evolution}

We noticed a good evolution, with no reappearance of infection in 21 patients. Two patients have been re-infected; one underwent removal of the device with surgical reimplantation and the other underwent extraction without reimplantation because he remained asymptomatic. No death reported in our series.

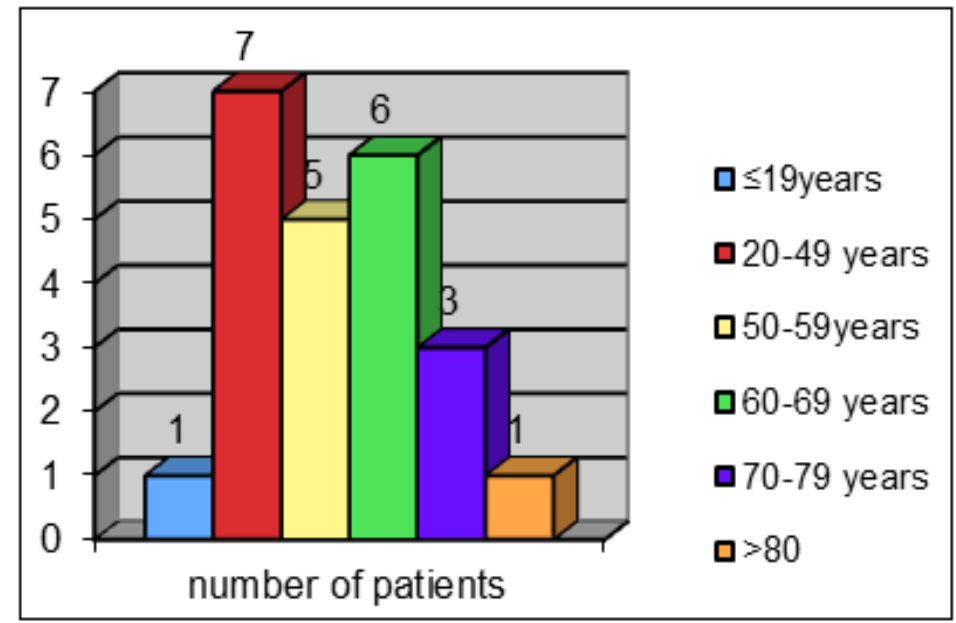

Fig-1: Different age groups of series 


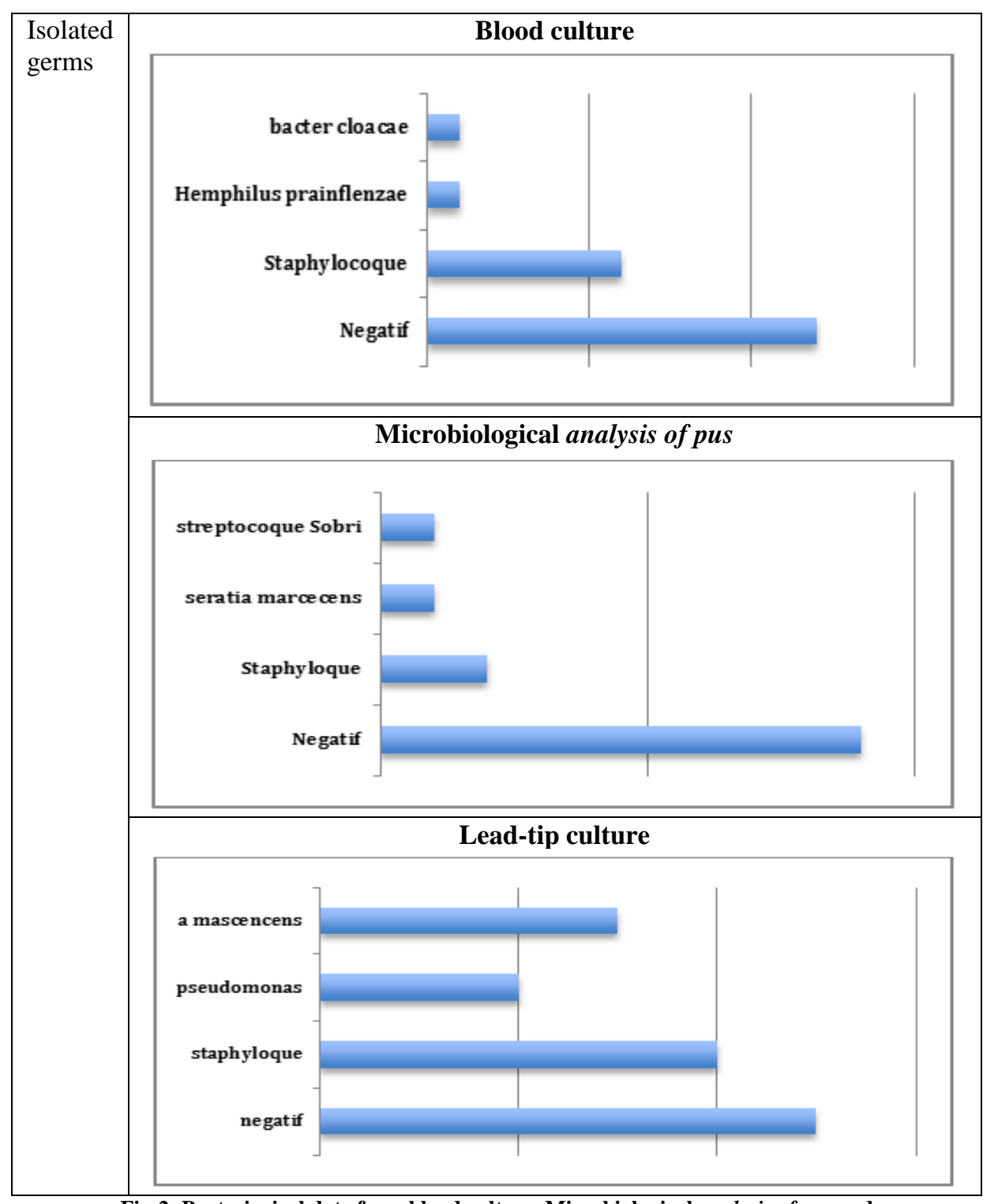

Fig-2: Bacteriogical data from blood culture, Microbiological analysis of pus and

Table-1: Clinical sign of sepsis, laboratory findings and echocardiographic data depending of types of infection: +:

\begin{tabular}{|c|c|c|c|c|c|c|c|c|}
\hline Types of infection & $\begin{array}{l}\text { Nb of patients } \\
(\%)\end{array}$ & Fever & chills & GB & CRP & $\begin{array}{l}\text { Blood } \\
\text { culture }\end{array}$ & vegetation & $\begin{array}{l}\text { Lead } \\
\text { culture }\end{array}$ \\
\hline $\begin{array}{l}\text { Uncomplicated pocket } \\
\text { infection }\end{array}$ & 8 & 1 patient & 1patient & - & - & - & - & $\begin{array}{l}+ \text { in } 2 \\
\text { patients }\end{array}$ \\
\hline \multirow[t]{4}{*}{$\begin{array}{l}\text { Complicated lead pocket } \\
\text { infection (10patients) }\end{array}$} & $4(40 \%)$ & - & - & - & - & - & + & $\begin{array}{l}+ \text { in } \\
\text { 3patients }\end{array}$ \\
\hline & $3(20 \%)$ & - & - & - & - & + & + & $\begin{array}{l}+ \text { in } 1 \\
\text { patients }\end{array}$ \\
\hline & $2(20 \%)$ & $\begin{array}{l}+ \text { in } \\
\text { 1patient }\end{array}$ & $\begin{array}{l}+ \text { in } \\
\text { 1patient }\end{array}$ & + & + & + & - & + \\
\hline & $1(20 \%)$ & $\begin{array}{l}+ \text { in } \\
\text { 1patient }\end{array}$ & - & + & + & - & + & + \\
\hline ICED-LI & 1 & + & + & + & + & + & + & + \\
\hline ICED-IE & 1 & + & + & + & + & + & + & + \\
\hline
\end{tabular}


Table-2: Risk factors found in our series

\begin{tabular}{|l|l|l|}
\hline Risk Factor of infection & Number of patients (\%) \\
\hline \multirow{3}{*}{ Host related Risk factor } & Male sexe & $18(78 \%)$ \\
\cline { 2 - 3 } & Age<60 & $13(56.5 \%)$ \\
\cline { 2 - 3 } & Diabetes mellitus & $9(39.1 \%)$ \\
\cline { 2 - 3 } $\begin{array}{l}\text { Procedure related risk } \\
\text { factor }\end{array}$ & $\begin{array}{l}\text { Need of reintervention (for lead dysfunction, post- } \\
\text { operative haematoma.) }\end{array}$ & $8(8.69 \%)$ \\
\cline { 2 - 3 } & Use of temporary pacemaker prior to implantation & $6(26 \%)$ \\
\cline { 2 - 3 } & Prolonged time of procedure(complexity) & $3(11 \%)$ \\
\hline
\end{tabular}

\section{DISCUSSION}

\section{Incidence}

The frequency of device-related infections in our center is $1.2 \%$. Similar results were reported by Olsen et al., (1.19\%) based on data from a Danish register of CIEDs [5]. In Japan, a survey of 129 institutes led by Nakajima et al., [6] found an incidence rate as low as ours (1.12\%). However, other studies have reported much higher infection rates, ranging from $1.9 \%$ [7] to $2.4 \%$ [8]. The low rate of infection in our center is due to systematic antibiotic prophylaxis prior to undertaking the procedure, local expertise, and fewer implanted CRTs.

\section{Risk Factor of Infection}

In our data, $78 \%$ of the patients infected were male. Male predominance has been noted in several studies. This is probably due to gender differences in bacterial skin colonization [9]. A younger age has also been associated with CIED infection [10, 11, 5], but the reasons remain unclear [5]. Conversely, the infection rate has been correlated with older ages in some studies $[12,13]$. Diabetes mellitus is known to be a risk factor for infection. In our data, $39.1 \%$ of the patients infected were diabetic. Similarly, Deniz et al., [13] found that $25.5 \%$ of patients infected were diabetic. This higher rate of infections for diabetics is due to several mechanisms that disrupt and delay wound healing $[14$, 13]. Olsen et al., [5] demonstrated that postoperative procedures relating to the device (such as fixing a lead dysfunction or draining a postoperative hematoma), except for changing the generator, contribute to an increased infection rate and can shorten the delay in the onset of symptoms. In fact, some patients quickly become infected after such postoperative procedures.

Six of our patients had a temporary wire fitted before implantation of their pacemaker. The rates of infections following the insertion of a temporary pacemaker range from $2 \%$ to $18 \%$ [15], which is probably related to bacteremia and occult sepsis induced by the external leads. In a prospective multicenter survey, we found that when a temporary wire was used, the odds ratio of infection was 2.46 (95\% CI 1.09-5.13) [16].

\section{Local infections are more frequent}

In our data, most patients $(78 \%)$ had signs of a local infection. Such infections may be limited to the wound site (i.e., an uncomplicated pocket infection) or be accompanied by systemic signs (i.e., a complicated pocket infection). Similarly, Marwan Refaat et al., [17] found that $59.1 \%$ of patients presented signs of generator pocket infection. Souhail et al., found that $69 \%$ of patients had such symptoms [18].

Table-1 shows that for four patients, a biological assessment and blood culture did not help in the diagnosis of complicated forms of infection, which were revealed only by the presence of vegetation. According to Golzio et al., [19], vegetation is frequently observed in patients with only local symptoms. These authors concluded that transesophageal echocardiography should be mandatory for patients with local signs, even if there has been a negative biological assessment. In fact, infections often involve the whole stimulation system and are not limited to the generator pocket [19]. Therefore, looking for vegetation is justified even when a patient has signs of only local infection.

\section{Inflammatory Biomarkers in Local Forms}

Inflammatory biomarkers have a low sensitivity in detecting cardiac device infection [18]. Contrary to what Lennerz et al., [20] found, CRP and procalcitonin did not help in diagnosis, particularly for complicated pocket infections. Therefore, in our opinion, testing for inflammatory biomarkers should not initially be considered for local cases of infection.

\section{Negative Bacteriological Results}

Another characteristic of our data is the number of bacteriological examinations with negative results of infection. Given the reasonable distance between the bacteriology laboratory and our center, the longer delivery times for samples may contribute to germs not being isolated. Preparing cultures with samples from the lead tip culture is the most sensitive form of bacteriological examination. Similarly, based on the available data on causative agents [20,21], staphylococci remain the most isolated forms of bacteria. 


\section{Management}

Patients with uncomplicated PI underwent local surgical revision and targeted antibiotic therapy. If signs of infection persisted, we often extracted the device. A systemic infection requires an immediate percutaneous extraction of the lead. Nevertheless, in the absence of any technical protection of the pulmonary bed, surgical extraction should be considered for a large vegetation.

Reimplantation is recommended if the necessity of CIED implantation is confirmed. According to the guidelines, reimplantation must be delayed to reduce the risk of reinfection $[4,22]$. In our clinical practice, even with local forms of infection, reimplantation is delayed until all clinical and bacteriological signs of infection have resolved.

\section{CONCLUSION}

In our context, ICED-related infection affects, mainly, young male patients and frequently diabetics. These patients usually have been surgically revised for postoperative complications or underwent temporary wire before implantation of cardiac device. Often, it is systemic forms induced by pocket infection. Biological et bacteriological tests are always negative. When the causative germ is isolated, it is often a staphylococcus. Thus, implantation of CIED in these patients must be carefully performed especially in diabetics. Surgical revisions have to be avoided as much as possible.

\section{REFERENCES}

1. Baddour LM, Epstein AE, Erickson CC, Knight BP, Levison ME, Lockhart PB, Masoudi FA, Okum EJ, Wilson WR, Beerman LB, Bolger AF. Update on cardiovascular implantable electronic device infections and their management: a scientific statement from the American Heart Association. Circulation. 2010 Jan 26;121(3):45877.

2. Greenspon AJ, Patel JD, Lau E, Ochoa JA, Frisch DR, Ho RT, Pavri BB, Kurtz SM. 16-year trends in the infection burden for pacemakers and implantable cardioverter-defibrillators in the United States: 1993 to 2008. Journal of the American College of Cardiology. 2011 Aug 30;58(10):1001-6.

3. Rundström $\mathrm{H}$, Kennergren $\mathrm{C}$, Andersson $\mathrm{R}$, Alestig K, Hogevik H. Pacemaker endocarditis during 18 years in Göteborg. Scandinavian journal of infectious diseases. 2004 Sep 1;36(9):674-9.

4. Sandoe JA, Malnick H, Loudon KW. A case of peritonitis caused by Roseomonas gilardii in a patient undergoing continuous ambulatory peritoneal dialysis. Journal of clinical microbiology. 1997 Aug 1;35(8):2150-2.

5. Olsen T, Jørgensen OD, Nielsen JC, Thøgersen AM, Philbert BT, Johansen JB. Incidence of device-related infection in 97750 patients: clinical data from the complete Danish device-cohort (1982-2018). European heart journal. 2019 Jun $14 ; 40(23): 1862-9$

6. Nakajima $H$, Taki $M$. Incidence of cardiac implantable electronic device infections and migrations in Japan: Results from a 129 institute survey. Journal of arrhythmia. 2016 Aug 1;32(4):303-7.

7. Rahman R, Saba S, Bazaz R, Gupta V, Pokrywka $\mathrm{M}$, Shutt K, Bridge C, Yassin MH. Infection and readmission rate of cardiac implantable electronic device insertions: an observational single center study. American journal of infection control. 2016 Mar 1;44(3):278-82.

8. Da Costa A, Tulane C, Dauphinot V, Terreaux J, Romeyer-Bouchard C, Gate-Martinet A, Levallois M, Isaaz K. Preoperative skin antiseptics for prevention of cardiac implantable electronic device infections: a historical-controlled interventional trial comparing aqueous against alcoholic povidone-iodine solutions. Ep Europace. 2015 Jul 1;17(7):1092-8.

9. Fierer N, Hamady M, Lauber CL, Knight R. The influence of sex, handedness, and washing on the diversity of hand surface bacteria. Proceedings of the National Academy of Sciences. 2008 Nov 18;105(46):17994-9.

10. Margey R, McCann H, Blake G, Keelan E, Galvin J, Lynch M, Mahon N, Sugrue D, O'Neill J. Contemporary management of and outcomes from cardiac device related infections. Europace. 2010 Jan 1;12(1):64-70.

11. Johansen JB, Jørgensen OD, Møller M, Arnsbo P, Mortensen PT, Nielsen JC. Infection after pacemaker implantation: infection rates and risk factors associated with infection in a populationbased cohort study of 46299 consecutive patients. European heart journal. 2011 Apr 1;32(8):991-8.

12. Duval X, Suty CS, Alla F, Salvador-Mazenq M, Bernard Y, Weber M, Lacassin F, Nazeyrolas P, Chidiac C, Hoen B, Leport C. Endocarditis in patients with a permanent pacemaker: a 1-year epidemiological survey on infective endocarditis due to valvular and/or pacemaker infection. Clinical infectious diseases. 2004 Jul 1;39(1):6874.

13. Deniz A, Karaaslan MB. The Infections of Cardiac Implantable Electronic Devices: Four Year Experience of a Single Center. Journal of Clinical and Experimental Investigations. 2017;9(2):67-70.

14. Gallego P, Apostolakis S, Lip GY. Bridging evidence-based practice and practice-based evidence in periprocedural anticoagulation. Circulation, 2012; 126:1573-1576.

15. McCann P. A review of temporary cardiac pacing wires. Indian pacing and electrophysiology journal. 2007 Jan;7(1):40-49.

16. Klug D, Balde M, Pavin D, Hidden-Lucet F, Clementy J, Sadoul N. Risk factors related to infections of implanted pacemakers and 
cardioverter-defibrillators. Circulation. 2007 citado 2014 May 18; 116(12):13.

17. Refaat M, Zakka P, Khoury M, Chami H, Mansour S, Harbieh B, Abi-Saleh B, Bizri AR. Cardiac implantable electronic device infections: Observational data from a tertiary care center in Lebanon. Medicine. 2019 Apr;98(16).

18. Sohail MR, Uslan DZ, Khan AH, Friedman PA, Hayes DL, Wilson WR, Steckelberg JM, Stoner S, Baddour LM. Management and outcome of permanent pacemaker and implantable cardioverter-defibrillator infections. Journal of the American College of Cardiology. 2007 May 8;49(18):1851-9.

19. Golzio PG, Fanelli AL, Vinci M, Pelissero E, Morello M, Grosso Marra W, Gaita F. Lead vegetations in patients with local and systemic cardiac device infections: prevalence, risk factors, and therapeutic effects. Europace. 2013 Jan 1;15(1):89-100.

20. Cajoto IV, Framil MR, Van den Eynde Collado A, Vicedo MJ, Romero CC. Permanent transvenous pacemaker infections: An analysis of 59 cases. European journal of internal medicine. 2007 Oct $1 ; 18(6): 484-8$.
21. Bongiorni MG, Tascini C, Tagliaferri E, Cori AD, Soldati E, Leonildi A, Zucchelli G, Ciullo I, Menichetti F. Microbiology of cardiac implantable electronic device infections. Europace. 2012 Sep 1;14(9):1334-9.

22. Habib G, Lancellotti P, Antunes MJ, Bongiorni MG, Casalta JP, Del Zotti F, Dulgheru R, El Khoury G, Erba PA, Iung B, Miro JM. 2015 ESC guidelines for the management of infective endocarditis: the task force for the management of infective endocarditis of the European Society of Cardiology (ESC) endorsed by: European Association for Cardio-Thoracic Surgery (EACTS), the European Association of Nuclear Medicine (EANM). European heart journal. 2015 Nov 21;36(44):3075-128.

23. Lennerz C, Vrazic H, Haller B, Braun S, Petzold T, Ott I, Lennerz A, Michel J, Blažek P, Deisenhofer I, Whittaker P. Biomarker-based diagnosis of pacemaker and implantable cardioverter defibrillator pocket infections: a prospective, multicentre, case-control evaluation. PloS one. 2017;12(3). 